\title{
Fixed-dose enoxaparin provides efficient DVT prophylaxis in mixed ICU patients despite low anti-Xa levels: A prospective observational cohort study
}

\author{
Jan Benes ${ }^{\mathrm{a}, \mathrm{b}}$, Roman Skulec ${ }^{\mathrm{a}, \mathrm{b}, \mathrm{c}, \mathrm{d}, \mathrm{h}, \mathrm{l}}$, Jakub Jobanek ${ }^{\mathrm{b}}$, Vladimir Cerny ${ }^{\mathrm{b}, \mathrm{c}, \mathrm{e}, \mathrm{f}, \mathrm{g}}$
}

Background. Deep vein thrombosis (DVT) is a serious but preventable complication of critical illness with a reported incidence from 4 to $17 \%$. Anti-Xa activity in critically ill patients achieved with standard dosing of low-molecular-weight heparins (LMWH) is often below the target of $0.2-0.5 \mathrm{IU} / \mathrm{mL}$. However, the clinical significance of this finding is unclear. The quality of thromboprophylaxis also strongly impacts the incidence of DVT. We performed a prospective observational study to evaluate the incidence of DVT in a mixed medical-surgical-trauma intensive care unit (ICU) using a thromboprophylaxis protocol with a fixed dose of enoxaparin. We also explored the relation between DVT incidence and anti-Xa activity.

Method. All consecutive patients with expected ICU stay $\geq 72$ hours and without evidence of DVT upon admission were included. They underwent ultrasound screening for DVT twice a week until ICU discharge, death, DVT or pulmonary embolism. Peak anti-Xa activity was measured twice a week. Patients received $40 \mathrm{mg}$ of enoxaparin subcutaneously (60 $\mathrm{mg}$ in obese, $20 \mathrm{mg}$ in case of renal failure). Graduated compression stockings were used in case of LMWH or another anticoagulant contraindication.

Results. A total of 219 patients were enrolled. We observed six cases of DVT (incidence of 2.7\%). The agreement between expected and delivered DVT prophylaxis was $94 \%$. Mean peak anti-Xa activity level was 0.24 (SD, 0.13$) \mathrm{IU} / \mathrm{mL}$. There was no significant difference in anti-Xa activity in DVT and non-DVT group.

Conclusion. A low incidence of DVT was achieved with meticulous adherence to the standard prophylactic protocol. The low incidence of DVT was observed despite low levels of anti-Xa activity. Our findings suggest that enoxaparin dose adjustment based on regular monitoring of anti-Xa activity is unlikely to result in further reduction of DVT incidence in a mixed ICU population.

Trial registration: ClinicalTrials.gov, NCT03286985.

Key words: venous thrombosis, thromboprophylaxis intensive care units, anti-Xa, enoxaparin, pulmonary embolism, compression ultrasound test

Received: October 19, 2020; Revised: May 4, 2021; Accepted: May 7, 2021; Available online: May 27, 2021

https://doi.org/10.5507/bp.2021.031

(c) 2022 The Authors; https://creativecommons.org/licenses/by/4.0/

${ }^{a}$ Faculty of Medicine in Hradec Kralove, Charles University in Prague and University Hospital Hradec Kralove, Czech Republic

${ }^{b}$ Deartment of Anesthesiology, Perioperative Medicine and Intensive Care Masaryk Hospital, J.E. Purkinje University, Usti nad Labem, Czech Republic

'Faculty of Health Studies, J.E. Purkinje University, Usti nad Labem, Czech Republic

${ }^{d}$ Department of Anesthesiology and Intensive Care, Faculty of Medicine in Hradec Kralove, Charles University in Prague and University Hospital Hradec Kralove, Czech Republic

${ }^{e}$ Center for Research and Development, Department of Anesthesiology and Intensive Care, Faculty of Medicine in Hradec Kralove, Charles University in Prague, Hradec Kralove, Czech Republic

${ }^{f}$ Department of Anesthesia, Pain Management and Perioperative Medicine, Dalhousie University, Halifax, Canada

${ }^{9}$ Constantine the Philosopher University in Nitra, Faculty of Social Sciences and Health Care, Slovak Republic

${ }^{h}$ Emergency Medical Service of the Central Bohemian Region, Czech Republic

Corresponding author: Jan Benes, e-mail:jan.benes@live.com

\section{INTRODUCTION}

Deep vein thrombosis (DVT) is a feared complication of critical illness despite routine prophylactic measures. The reported incidence of DVT varies widely from 4 to $17 \%$, but it has been declining over the past two decades ${ }^{1-8}$. The incidence of DVT in critically ill patients has likely decreased due to the widespread use of prophylactic anticoagulation but also thanks to the changes in critical care practice such as less sedation, less muscle paralysis, less steroids, more frequent use of non-invasive ventilation and earlier mobilization. Low molecular weight heparin (LMWH) has been adopted as an anticoagulant of choice for DVT prophylaxis9. However, several studies have shown that standard dosing of enoxaparin, one of the frequently used LMWH, yields low levels of anti-Xa activity in critically ill patients ${ }^{10,11}$. Levels of anti-Xa activity serve as a marker of anticoagulation effect and low values may signal insufficient dosing and therefore inadequate prophylaxis of DVT. The clinical significance of this concept remains controversial in critically ill patients and current guidelines do not recommend routine measurement of 
anti-Xa activity and dose targeting ${ }^{12}$. Nevertheless, some researchers argue that targeting the dose of enoxaparin to anti-Xa level should be considered ${ }^{13-15}$, while others advise otherwise ${ }^{6}$. Also, the target levels of anti-Xa has not been established for critically ill patients. Generally accepted target levels between $0.2 \mathrm{IU} / \mathrm{mL}$ and $0.5 \mathrm{IU} / \mathrm{mL}$ are derived mostly from non-critically ill surgical patient population ${ }^{16}$. Data from mixed intensive care unit (ICU) patients are lacking. Therefore, we performed a prospective observational study to evaluate the incidence of DVT in the mixed ICU population, in relation to the adherence to the thromboprophylaxis guidelines. We also analyzed whether anti-Xa levels reflect thromboprophylaxis efficiency of a non-adjusted dose of enoxaparin in mixed ICU population.

\section{METHODS}

\section{Study design}

We conducted a single-center prospective observational cohort study of patients admitted to the mixed intensive care unit of the Department of Anesthesiology, Perioperative Medicine and Intensive Care, at J.E. Purkinje University, Masaryk Hospital, Usti nad Labem, Czech Rebublic, a tertiary university hospital.

\section{Selection of participants}

Consecutive patients admitted to the ICU between September 2017 and July 2018 were screened for eligibility. Inclusion criteria were as follows: at least 18 years of age, expected ICU stay at least $72 \mathrm{~h}$ and negative baseline ultrasound compression test (UCT). Exclusion criteria were as follows: known DVT or pulmonary embolism $(\mathrm{PE})$, contraindication of ultrasound examination of venous system of lower extremities (allergy to ultrasound gel or major bilateral limb injury), disagreement with ultrasound examination in conscious patients and patient participation in another clinical trial. Sample size analysis was performed under the assumption of $10 \%$ incidence of DVT as published previously with further assumption that our protocol could decrease the incidence to $5 \%$. Given power of $70 \%$, chi-square statistics determines the sample size at alpha level of 5\% to 192 probands. The screening period was restricted to 9 months because of limited resources.

\section{Study protocol}

All patients admitted to the ICU were assessed for eligibility. First, compliance with clinical and ethical criteria was assessed. In those who met the criteria, a baseline UCT was performed within $48 \mathrm{~h}$ after admission. Subjects with negative baseline UCT were enrolled in the study and underwent further investigations. The investigators performed regular UCT ultrasound examinations twice a week until ICU discharge, death or diagnosis of DVT or PE. We assessed and recorded compliance with the local thromboprophylaxis protocol on each day of UCT examination. Plasma levels of D-dimer and peak levels of anti-Xa activity were measured twice a week.

\section{Study interventions}

We applied prophylactic measures to all patients admitted to the ICU according to the local protocol following the Antithrombotic Therapy and Prevention of Thrombosis, 9th ed: American College of Chest Physicians EvidenceBased Clinical Practice Guidelines ${ }^{12}$. Patients received 40 mg of subcutaneous enoxaparin once daily. Treating physicians reduced the dose to $20 \mathrm{mg}$ once daily in case of renal failure with creatinine clearance lower than $30 \mathrm{~mL} / \mathrm{min}$. Patients with body mass index over 35 or patients with severe generalized edema received $60 \mathrm{mg}$ of enoxaparin once daily. In case of allergy to enoxaparin, suspected or known heparin-induced thrombocytopenia, physicians prescribed $2.5 \mathrm{mg}$ of fondaparinux subcutaneously once daily or 1.5 $\mathrm{mg}$ once daily in case of renal failure. Anticoagulation initiation was postponed in patients with significant active bleeding or high risk of severe bleeding until the administration of anticoagulant was considered safe. Enoxaparin was not administered sooner than $12 \mathrm{~h}$ after major trauma, abdominal, thoracic, or orthopedic surgery, $24 \mathrm{~h}$ after brain and spinal surgery or non-traumatic intracranial bleeding and $48 \mathrm{~h}$ in case of traumatic brain injury with intracranial bleeding. All patients received graduated compression stockings until anticoagulation was initiated. If significant bleeding occurred, the treating physician could either withhold enoxaparin temporarily or reduce the dose. All patients were considered to be at high risk of DVT, therefore, we applied the same prophylactic measures in patients with any known specific risk factors of DVT (i.e. thrombophilia, tumors etc.). Therapeutic dose of anticoagulant or concomitant antiplatelet therapy was provided if indicated. Compliance with the DVT prophylaxis protocol was recorded twice weekly.

Ultrasound examinations were performed using Vivid S6 or Vivid T8 machines (GE Healthcare, Chicago, Illinois, USA) equipped with high-resolution linear transducer set to $5.0-7.0 \mathrm{MHz}$. The transducer was set at a frequency of 5.0-7.0 MHz and image depth was adjusted to $4 \mathrm{~cm}$. All examinations were done using B-mode imaging. Patients were in supine position for femoral vein examination with bent knee and externally rotated hip for popliteal vein visualization. The transducer was placed in transverse position with the vein at the center of the image. Appropriate amount of pressure was applied, which was just enough to cause some degree of deformation to the adjacent artery. Image quality was graded as excellent, low-quality or unable to visualize. The vein was classified as either fully compressible or partially compressible or incompressible. Thrombus presence was recorded. The extent of examination was 2-region UCT. The investigators examined the proximal venous system in the leg starting from the inguinal ligament and documented compressibility and thrombus presence at five sites: proximal common femoral, the confluence of femoral with great saphenous vein, the superficial and deep femoral veins bifurcation, popliteal veins and the venous trifurcation. A partially or completely incompressible vein segment or direct visualization of a blood clot was diagnostic for deep vein thrombosis. A certified radiologist checked all positive or inconclusive findings. 
Anti-Xa activity was analyzed using a chromogenic assay kit with standard calibration (INNOVANCE ${ }^{\circledR}$ Heparin, Siemens Healthcare Diagnostics), samples were drawn 4 hours after enoxaparin administration, D-Dimer levels were analyzed with immunoturbidimetric assay (STA Liatest D-Di, STAGO). Target level of anti-Xa activity for prophylactic dosing was $0.2-0.5 \mathrm{IU} / \mathrm{mL}$.

\section{Training of investigators}

The investigators had previous experience in vascular Point-of-Care ultrasound at different levels. All had had two hours of formal training in UCT examination including practical demonstration of UCT and examined five patients under the supervision of an expert in Point-ofCare vascular ultrasound before the initiation of the study.

\section{Outcomes}

The primary outcome was the incidence of proximal deep vein thrombosis. This was defined as a new-onset DVT diagnosed between enrollment and ICU discharge.

Secondary outcomes were the incidence of pulmonary embolism, the number of major bleeding events, the adherence to the thromboprophylaxis protocol, the levels and course of anti-Xa activity, and the level of plasmatic D-dimer, ICU mortality, length of ICU stay and duration of mechanical ventilation.

Major bleeding was defined in accordance with the Subcommittee on Control of Anticoagulation of the Scientific and Standardization Committee of the International Society on Thrombosis and Haemostasis ${ }^{17,18}$ as fatal bleeding or bleeding that is symptomatic and occurs in a critical area or organ, such as intracranial, intraspinal, intraocular, retroperitoneal, pericardial, in a non-operated joint, or intramuscular with compartment syndrome; assessed in consultation with the surgeon or extra surgical site bleeding causing a fall in hemoglobin level of $20 \mathrm{~g} / \mathrm{L}$ or more; or leading to transfusion of two or more units of whole blood or red cells, with temporal association within $24-48 \mathrm{~h}$ to the bleeding or surgical site bleeding that requires a second intervention, open, arthroscopic, endovascular; or a hemarthrosis of sufficient size as to interfere with rehabilitation by delaying mobilization or delayed wound healing; resulting in prolonged hospitalization or a deep wound infection or surgical site bleeding that is unexpected and prolonged or sufficiently large to cause hemodynamic instability.

\section{Statistical analysis}

Comparisons of continuous variables were made using two-tailed t-tests or Mann-Whitney U tests as appropriate according to variable distribution. Comparisons of categorical variables were done using chi-square or Fisher exact test as appropriate. In all cases a p-value of less than 0.05 was considered significant. All computations were performed using STATISTICA 13.5 software.
Table 1. Baseline characteristic of the patient population.

\begin{tabular}{lc}
\hline Age, mean (SD) years & $61.1(16.3)$ \\
Female sex, no (\%) & $79(36 \%)$ \\
SAPS II, mean (SD) & $61.1(19.9)$ \\
Body-mass index, mean (SD) kg/m² & $28.7(6.7)$ \\
Body weight, mean (SD) kg & $85.1(21.5)$ \\
Type of admission (mutually exclusive) no. (\%) & \\
Medical & $83(37.9 \%)$ \\
Surgical & $64(29.2 \%)$ \\
Trauma & $63(28.8 \%)$ \\
Post CPR & $9(4.1 \%)$ \\
Diagnosis on admission no. $(\%)$ & \\
Sepsis & $70(32.0 \%)$ \\
Respiratory failure & $116(53.0 \%)$ \\
Traumatic brain injury & $28(12.8 \%)$ \\
Spinal cord injury & $7(3.2 \%)$ \\
Multiple trauma & $31(14.2 \%)$ \\
Major surgery & $90(41.1 \%)$ \\
Stroke & $40(18.3 \%)$ \\
Acute myocardial infarction & $2(0.9 \%)$ \\
Pregnancy & $1(0.5 \%)$ \\
Other & $32(14.6 \%)$ \\
\hline
\end{tabular}

SAPS, Simplified Acute Physiology Score; CPR, cardiopulmonary resuscitation

\section{RESULTS}

A total of 225 patients were assessed for eligibility. We excluded two patients with positive baseline UCT for deep vein thrombosis. Four patients were excluded due to the failure to obtain baseline ultrasound. A total of 219 patients underwent further analysis.

The baseline characteristics of the patients are shown in Table 1. We identified six patients who developed deep vein thrombosis during their ICU stay, for an incidence of $2.7 \%$. We found thrombosis in the left femoral vein in three cases, in the right femoral vein in one case and the left popliteal vein in two cases. There was a complete thrombosis of the left femoral vein in one case and of the popliteal vein in two cases. Partial thrombosis was identified in the remaining three cases. The diagnosis of DVT was made between day four and 25 (median 9.5) of the ICU stay. All cases were asymptomatic, with no prior clinical suspicion of DVT. There were no cases of pulmonary embolism.

The agreement between expected and delivered DVT prophylaxis was $94 \%$ for pharmacological and $95 \%$ for mechanical prophylaxis. In our sample, 170 (77\%) patients received enoxaparin in prophylactic regimen, 32 (15\%) patients received therapeutic dose of enoxaparin or heparin during their ICU stay for a diagnosis other than DVT. In 17 patients (7.8\%), only mechanical thromboprophylaxis with graduated compression stockings was applied during the study period.

The mean dose of prophylactic enoxaparin was 0.41 $\mathrm{mg}$ (SD, 8.8), this yields a mean level of pooled measurements of anti-Xa activity of $0.24 \mathrm{IU} / \mathrm{mL}$ (SD, 0.13). 30\% of all measurements of peak anti-Xa activity in patients 
receiving prophylactic enoxaparin were below the lower threshold of $0.2 \mathrm{IU} / \mathrm{mL}$, and another $30 \%$ just reached this threshold. No cases of enoxaparin accumulation were identified. There was no statistically significant association between anti-Xa levels and enoxaparin dose, body weight, vasopressor dose, type of patient or renal function. Fig. 1 shows the distribution of anti-Xa activity over days after the ICU admission. The median level of pooled measurements of D-dimer was 1.66 (IQR, 1.7-6.5).

Nine $(4.1 \%)$ patients experienced a major bleeding event, two of them were fatal. The bleeding events are described in detail in Table 4.

A total of $23(11.9 \%)$ patients died during ICU stay. The median length of ICU stay was 4 days (IQR, 4-12). A total of 144 (66\%) of patients required invasive mechanical ventilation during the study period with a median duration of 4 days (IQR, 3-9). Table 3 shows the differences in outcomes between patients who developed DVT and those who did not.

\section{DISCUSSION}

The main finding of our study is that a very low incidence of DVT $(2.7 \%)$ can be achieved with strict adherence to the DVT prophylaxis protocol using a fixed dose of enoxaparin and graduated compression stockings. We observed this low incidence of DVT despite low and heterogeneous levels of anti-Xa activity which poorly reflected standard prophylactic dosing of enoxaparin.

Reasons for the low and very heterogenous levels of anti-Xa activity in critically ill patients are not clear. A possible reason could be reduced absorption of subcutaneous heparin because of pharmacological or spontaneous vasoconstriction or subcutaneous edema. Additionally, drug metabolism, distribution and protein binding may be altered by multiple organ dysfunction and augmented renal function often present in critically ill patients may enhance elimination.

Deep vein thrombosis is a common complication in critically ill patients, but the reported incidence varies widely from $4.3 \%$ to $16.9 \%$ (ref. $^{1-7}$ ). Studies that reported a low incidence of DVT (ref. ${ }^{2,5-7}$ ) that was close to our results, share several general characteristics and similarities with our study. First, the studies were published in the last 10 years and reflect recent practice of critical care. Second, they exhibit a similar design of early initiation of thromboprophylactic measures with high degree of adherence to it. Cook et al. prospectively evaluated the incidence of DVT in 1873 mixed ICU patients and found the incidence of DVT to be $5.1 \%$. Adherence to the thromboprophylaxis protocol was $96.7 \%$ (ref. $^{2}$ ). Boddi et al. found a reduction of DVT incidence from 11.6.\% to $4.7 \%$ after a one-year educational program focused on improvement in DVT prophylaxis ${ }^{5}$. They reported the use of anticoagulant in $96.1 \%$ of patients and graduated compressive stockings in $59.5 \%$.

On the other hand, studies that reported a higher incidence of DVT were published earlier (except for the study of Skrifvars et al. ${ }^{4}$ ) and the day of initiation of
Table 2. Risk factors of deep vein thrombosis.

\begin{tabular}{|c|c|}
\hline Diabetes no. $(\%)$ & $70(32.0)$ \\
\hline Ischemic heart disease no. (\%) & $32(14.6)$ \\
\hline Heart failure no. $(\%)$ & $15(6.9)$ \\
\hline Arterial hypertension no. (\%) & $136(62.1)$ \\
\hline Stroke no. $(\%)$ & $23(10.5)$ \\
\hline Paresis no. (\%) & $39(17.8)$ \\
\hline Smoking no. (\%) & $64(29.2)$ \\
\hline Renal failure no. (\%) & $21(9.6)$ \\
\hline Hemodialysis no. (\%) & $6(2.7)$ \\
\hline Chronic lung condition no. (\%) & $42(19.2)$ \\
\hline Anticoagulation treatment no. (\%) & $23(10.5)$ \\
\hline Antiplatelet treatment no. (\%) & $44(20.1)$ \\
\hline Bleeding disorder no. (\%) & $0(0)$ \\
\hline Factor V Leiden no. (\%) & $3(1.4)$ \\
\hline Factor II mutation no. (\%) & $0(0)$ \\
\hline Hyperhomocysteinemia no. (\%) & $1(0.5)$ \\
\hline Lupus anticoagulant no. (\%) & $0(0)$ \\
\hline Heparin induced thrombocytopenia no. (\%) & $0(0)$ \\
\hline Other thrombotic condition no. (\%) & $1(0.5)$ \\
\hline \multicolumn{2}{|l|}{ Venous thromboembolism no. (\%) } \\
\hline Personal history & $6(2.7)$ \\
\hline Family history & $6(2.7)$ \\
\hline Active malignancy no. (\%) & $33(15.1)$ \\
\hline History of malignancy no. (\%) & $31(14.2)$ \\
\hline Inflammatory disease no. $(\%)$ & $7(3.2)$ \\
\hline $\begin{array}{l}\text { Orthopedic surgery (hip, pelvis, leg } \\
\text { fracture or elective major lower extremity } \\
\text { arthroplasty }<1 \text { month) no. }(\%)\end{array}$ & $4(1.8)$ \\
\hline $\begin{array}{l}\text { Oral contraceptives or hormone } \\
\text { replacement therapy no. }(\%)\end{array}$ & $3(1.4)$ \\
\hline Sepsis history $<1$ month no. (\%) & $27(12.3)$ \\
\hline Pulmonary condition $<1$ month no. (\%) & $24(11.0)$ \\
\hline Major surgery $<1$ month no. (\%) & $28(12.8)$ \\
\hline Multiple trauma $<1$ month no. $(\%)$ & $6(2.7)$ \\
\hline Immobilizing plaster cast $<1$ month no. (\%) & $2(0.9)$ \\
\hline Confined to bed $>72$ h no. $(\%)$ & $53(24.2)$ \\
\hline \multicolumn{2}{|l|}{ Local signs on legs on admission no. (\%) } \\
\hline Varicose veins & $50(22.8)$ \\
\hline Swollen legs (bi- or unilateral) & $31(14.2)$ \\
\hline Chronic venous insufficiency & $62(28.3)$ \\
\hline Skin defect & $24(11.0)$ \\
\hline Inflammation & $14(6.4)$ \\
\hline Caprini score mean (SD) & $9.6 \pm 3.8$ \\
\hline Mechanical ventilation no. (\%) & $144(65.8)$ \\
\hline Vasopressors no. (\%) & $132(60.3)$ \\
\hline \multicolumn{2}{|l|}{ Dialysis no. $(\%)$} \\
\hline Any & $20(9.1)$ \\
\hline Continuous hemodialysis & $20(9.1)$ \\
\hline \multicolumn{2}{|l|}{ Central venous catheter no. (\%) } \\
\hline Femoral vein & $5(2.2)$ \\
\hline Other & $182(83.1)$ \\
\hline Transfusion no. (\%) & $86(39.3)$ \\
\hline
\end{tabular}

pharmacological prophylaxis was either not reported $d^{1,3}$ or late ${ }^{4}$. Of note is a very high incidence of DVT in the Skrifvars's post hoc analysis of the EPO-TBI trial of $16.9 \%$ which greatly exceeds reported incidence of DVT over the 
Table 3. Outcomes ICU.

\begin{tabular}{|c|c|c|c|c|}
\hline Outcome & Total & DVT & No DVT & $P$ \\
\hline Enoxaparin dose, mean (SD) mg & $41.0(8.8)^{*}$ & $56(32.3)^{+}$ & $43(12.7)^{+}$ & 0.29 \\
\hline anti-Xa, mean (SD) IU/mL & $0.24(0.13)^{*}$ & $0.32(0.15)^{+}$ & $0.26(0.16)^{+}$ & 0.10 \\
\hline D-dimer, median (IQR) mg/mL & $3.3(1.7-6.5)$ & $4.3(1.5-5.5)$ & $3.0(1.8-5.9)$ & 0.79 \\
\hline ICU stay, median (IQR) days & $4(4-12)$ & $20.5(8-28)$ & $5(3-11)$ & 0.11 \\
\hline ICU mortality, no. & $23 / 219(10.5 \%)$ & $1 / 6(17 \%)$ & $22 / 213(10 \%)$ & 0.49 \\
\hline Invasive mechanical ventilation, no. & $144 / 219(65.8 \%)$ & $5 / 6(83 \%)$ & $139 / 213(65 \%)$ & 0.66 \\
\hline $\begin{array}{l}\text { Duration of mechanical ventilation, median } \\
\text { (IQR) days }\end{array}$ & $4(3-9)$ & $4(2.5-23.5)$ & $4(3-9)$ & 0.33 \\
\hline
\end{tabular}

*prophylactic enoxaparin only

+prophylactic and therapeutic enoxaparin (started before DVT diagnosis in other indication)

Table 4. Major bleeding events.

\begin{tabular}{|c|c|c|c|c|c|c|}
\hline $\begin{array}{l}\text { Event } \\
\text { No. }\end{array}$ & Site of bleeding & $\begin{array}{l}\text { Type of } \\
\text { patient* }\end{array}$ & Fatal & Anticoagulation & $\begin{array}{l}\text { Antiplatelet } \\
\text { therapy }\end{array}$ & Medication change \\
\hline 1 & Gastric & $\mathrm{S}$ & No & Prophylactic & None & LMWH withheld \\
\hline 2 & Abdominal wall & M & No & None & Dual & None \\
\hline 3 & Post craniectomy epidural hematoma & $\mathrm{S}$ & No & Prophylactic & None & LMWH withheld \\
\hline 4 & GIT & M & No & Prophylactic & None & Dose reduction \\
\hline 5 & Intraparenchymal brain hemorrhage & $\mathrm{T}$ & Yes & Prophylactic & None & LMWH withheld \\
\hline 6 & Post resection cavity brain hemorrhage & S & Yes & $\begin{array}{l}\text { Therapeutic for new } \\
\text { onset DVT }\end{array}$ & None & LMWH withheld \\
\hline 7 & Liver surgical site & $\mathrm{S}$ & No & $\begin{array}{l}\text { Therapeutic for other } \\
\text { reason than DVT }\end{array}$ & None & Dose reduction \\
\hline 8 & GIT & $\mathrm{S}$ & No & Prophylactic & None & LMWH withheld \\
\hline 9 & Urinary bladder & $\mathrm{T}$ & No & Prophylactic & None & None \\
\hline
\end{tabular}

*S, surgical; M, medical; T, trauma

last decade. One possible explanation could be the very late initiation of pharmacological thromboprophylaxis. The authors reported that only $30 \%$ of patients received anticoagulant by day three and $57 \%$ by day seven and concluded that future studies should explore earlier initiation of pharmacological thromboprophylaxis in TBI patients ${ }^{4}$. In our cohort, there were 28 (13\%) TBI patients and one of them developed DVT, which is below the incidence reported in the EPO-TBI trial. We speculate that the possible reason for the difference could be the earlier administration of anticoagulant in our subgroup of TBI patients ( $41 \%$ received enoxaparin by day three and $90 \%$ by day seven).

In principle, there are two approaches to pharmacological thromboprophylaxis in critically ill patients: the uniform general approach based on the predefined fixed doses of enoxaparin and the personalized approach based on repeated measurements of anti-Xa activity ${ }^{6,14}$ or other markers of coagulation such as thromboelastometry ${ }^{7}$ followed by titration of the dose to reach the target. Several authors suggested that titrating the dose of enoxaparin based on peak or trough anti-Xa levels may be useful in reducing DVT rate ${ }^{14,19}$. In our study, we chose the uniform approach with emphasis on maximum adherence to the thromboprophylaxis protocol. Other measures, such as timely mobilization, minimal sedation and frequent spontaneous breathing trials were also part of the routine.
This approach led to very heterogeneous and generally low levels of anticoagulant activity in our clinical study. Up to one-third of the patients never reached the target level of anti-Xa activity of $0.2 \mathrm{IU} / \mathrm{mL}$. Despite this laboratory findings we found a very low incidence of DVT. Our study supports the recent finding of Karcutskie et al. ${ }^{6}$ who retrospectively compared the incidence of DVT reached with individualized dose of enoxaparin targeted to anti-Xa level with fixed dose in 792 trauma patients. They found a similar rate of DVT of $5.0 \%$ and $4.0 \%$ for the individualized and fixed dose regimens, respectively. They concluded that targeting the dose to the anti-Xa activity levels may not be as useful as previously suggested in critically ill trauma patients. Based on our results we may extend this finding to mixed ICU population including high-risk TBI patients. Predefined fixed dose of timely administered enoxaparin together with mechanical prophylaxis can provide efficient and safe thromboprophylaxis. We conclude that rather than costly and possibly futile anti-Xa based titration of enoxaparin, robust protocol with excellent adherence might be sufficiently effective in reducing the incidence of DVT among critically ill.

Secondary outcomes did not significantly differ between DVT and non-DVT patients. There was a trend toward longer ICU stay in DVT patients. However, DVT is not likely the cause of the longer ICU stay as all cases were asymptomatic and developed later during ICU stay. 
Paradoxically, we observed a trend toward higher antiXa levels in DVT patients in comparison to non-DVT patients. Higher anti-Xa levels observed in the group of DVT patients could be caused by therapeutic doses of enoxaparin prescribed in two DVT patients for atrial fibrillation before the development of DVT.

We recognize several limitations of the study. First and foremost, we identified a low number of DVT cases. Therefore, we were not able to perform reliable analysis of any potential risk factors associated with DVT. However, they have been reported elsewhere ${ }^{3}$ and are well established. Also the comparison of secondary outcomes between DVT nad non-DVT cases is of limited value because of the low number of DVT cases. Second, treating physicians were not blind to the anti-Xa levels. The unblinding could lead to enoxaparin dose adjustments. Anyhow, we did not observe the dose adjustment. Third, we did not carry out systematic detection of pulmonary embolism. This was done only on clinical suspicion. Fourth, we did not perform daily UCT screening of DVT. Therefore, the day of hospitalization on which DVT was diagnosed may not have been the day of onset. Fifth, a baseline UCT was not always performed immediately upon admission but was within the first 48 hours. However, DVT in the two excluded patients was diagnosed very quickly within four hours from admission. Sixth, we decided not to exclude patients who received therapeutic dose of anticoagulant or antiplatelet therapy during ICU stay for a diagnosis other than DVT. Therapeutic anticoagulation is very often temporarily withheld upon admission to the ICU and these patients might be at even higher risk of DVT. Therefore, we decided not to exclude these patients to get a complete and real-life picture of DVT incidence in a mixed ICU patient population. Patients who received therapeutic anticoagulation were excluded from the analysis of anti-Xa activity. Seventh, the patient population is very heterogenous with different reasons for admission which could complicate the interpretation of results. However, if we look at the data from the perspective of prophylactic protocol, this limitation might be also seen as a strength, because we showed, that the simple and universal protocol performed well even in this very heterogenous patient population. Eight, we did not collect the data on noninvasive ventilation, only invasive mechanical ventilation is reported.

\section{CONCLUSIONS}

Very low incidence of DVT in mixed ICU patients can be achieved by meticulous adherence to the standard prophylactic protocol following current guidelines. The study suggests that enoxaparin dose adjustment based on regular monitoring of anti-Xa activity is unlikely to result in further reduction of DVT incidence in mixed ICU population.

\section{ABBREVIATIONS}

DVT, Deep vein thrombosis; ICU, Intensive care unit; IQR, Interquartile range; LMWH, Low molecular weight heparin; UCT, Ultrasound compression test; PE, Pulmonary embolism; SD, standard deviation.

Acknowledgements: Supported by institutional grant no. IGA-KZ-2016-2-9 of Internal Grant Agency of Krajska zdravotni a.s., Czech Republic. We acknowledge the work of Eva Provaznikova MD, Martin David MD, Stanislav Polansky MD, Jan Bilik MD, Pavel Oravec MD and Xaya Waicova MD for patient recruitment and ultrasound examinations. We also acknowledge Ondrej Bradac MD for statistical analysis and Zdenka Dubnova for data collection and management.

Author contributions: JB: designed the study, undertook recruitment, analyzed and interpreted data and prepared the manuscript; RS: contributed substantially to the study design, data analysis and interpretation and manuscript preparation; JJ: analyzed and interpreted patient data regarding the DVT and bleeding complications; VC: was the senior researcher; he designed the trial, provided quality control and contributed substantially to data analysis and manuscript preparation.

Conflict of interest statement: The authors state that there are no conflicts of interest regarding the publication of this article.

\section{REFERENCES}

1. Fraisse F, Holzapfel L, Couland JM, Simonneau G, Bedock B, Feissel $M$, Herbecq P, Pordes R, Poussel JF, Roux L. Nadroparin in the prevention of deep vein thrombosis in acute decompensated COPD. The Association of Non-University Affiliated Intensive Care Specialist Physicians of France. Am J Respir Crit Care Med 2000;161(4 Pt 1):1109-14. doi:10.1164/ajrccm.161.4.9807025

2. Cook D, Meade M, Guyatt G, Walter S, Heels-Ansdell D, Warkentin TE, Zytaruk N, Crowther M, Geerts W, Cooper DJ, Vallance S, Qushmaq I, Rocha M, Berwanger O, Vlahakis NE. Dalteparin versus unfractionated heparin in critically ill patients. N Engl J Med 2011;364(14):130514. doi:10.1056/NEJMoa1014475

3. Cook D, Crowther M, Meade M, Rabbat C, Griffith L, Schiff D, Geerts W, Guyatt G. Deep venous thrombosis in medical-surgical critically ill patients: prevalence, incidence, and risk factors. Crit Care Med 2005;33(7):1565-71. doi:10.1097/01.ccm.0000171207.95319.b2

4. Skrifvars MB, Bailey M, Presneill J, French C, Nichol A, Little L, Duranteau J, Huet O, Haddad S, Arabi Y, McArthur C, Cooper DJ, Bellomo R, EPO-TBI investigators and the ANZICS Clinical Trials Group. Venous thromboembolic events in critically ill traumatic brain injury patients. Intensive Care Med 2017;43(3):419-28. doi:10.1007/ s00134-016-4655-2

5. Boddi M, Barbani F, Abbate R, Bonizzoli M, Batacchi S, Lucente E, Chiostri M, Gensini GF, Peris A. Reduction in deep vein thrombosis incidence in intensive care after a clinician education program. J Thromb Haemost 2010;8(1):121-28. doi:10.1111/j.15387836.2009.03664.x

6. Karcutskie CA, Dharmaraja A, Patel J, Eidelson SA, Padiadpu AB, Martin AG, Lama G, Lineen EB, Namias N, Schulman Cl, Proctor KG. Association of Anti-Factor Xa-Guided Dosing of Enoxaparin With Venous Thromboembolism After Trauma. JAMA Surg 2018;153(2):144. doi:10.1001/jamasurg.2017.3787

7. Connelly CR, Van PY, Hart KD, Louis SG, Fair KA, Erickson AS, Rick EA, Simeon EC, Bulger EM, Arbabi S, Holcomb JB, Moore LJ, Schreiber MA. Thrombelastography-based dosing of enoxaparin for throm- 
boprophylaxis in trauma and surgical patients: A randomized clinical trial. JAMA Surg 2019;151(10): e162069. doi:10.1001/jamasurg.2016.2069

8. Arabi YM, Al-Hameed F, Burns KEA, Mehta S, Alsolamy SJ, Alshahrani MS, Mandourah Y, Almekhlafi GA, Almaani M, Al Bshabshe A, Finfer S, Arshad Z, Khalid I, Mehta Y, Gaur A, Hawa H, Buscher $\mathrm{H}$, Lababidi H, Al Aithan A, Abdukahil SAI, Jose J, Afesh LY, AlDawood A. Adjunctive Intermittent Pneumatic Compression for Venous Thromboprophylaxis. N Engl J Med 2019;380(14):1305-15 doi:10.1056/NEJMoa1816150

9. Minet $C$, Potton L, Bonadona A, Hamidfar-Roy R, Somohano CA Lugosi M, Cartier J-C, Ferretti G, Schwebel C, Timsit J-F, Perkins G, McAuley D, Davies S, Gao F, McLeod A, Geerts W, Konstantinides S, Moser K, LeMoine J, Nachtwey F, Spragg R, Cade J, Kapoor M, Kupfer Y, Tessler S, Fraisse F, Holzapfel L, Couland J, Simonneau G, Bedock B, Feissel M, Cook D, Meade M, Guyatt G, Walter S, Heels-Ansdel D, Warkentin T, Cook D, Crowther M, Meade M, Rabbat C, Griffith L, Schiff D, Ibrahim E, Iregui M, Prentice D, Sherman G, Kollef M Shannon W, Harris L, Curl G, Booth F, Hassett J, Leney G, Ricotta J, Hirsch D, Ingenito E, Goldhaber S, Schultz D, Brasel K, Washington L, Goodman L, Quickel R, Lipchik R, Patel R, Cook D, Meade M, Griffith L, Mehta G, Rocker G, Bahloul M, Chaari A, Kallel H, Abid L, Hamida C, Dammak H, Bahloul M, Chaari A, Dammak H, Medhioub F, Abid L, Ksibi H, Minet C, Lugosi M, Savoye P, Menez C, Ruckly S, Bonadona A, Goldhaber S, Visani L, Rosa M, Torbicki A, Perrier A, Konstantinides S, Agnelli G, Galie N, Pruszczyk P, Wells P, et al. Venous thromboembolism in the ICU: main characteristics, diagnosis and thromboprophylaxis. Crit Care 2015;19(1):287. doi:10.1186/s13054-015-1003-9

10. Robinson S, Zincuk A, Larsen UL, Ekstrøm C, Nybo M, Rasmussen $B$, Toft P. A comparative study of varying doses of enoxaparin for thromboprophylaxis in critically ill patients: a double-blinded, randomised controlled trial. Crit Care 2013;17(2):R75. doi:10.1186/ cc12684

11. Malinoski D, Jafari F, Ewing T, Ardary C, Conniff H, Baje M, Kong A, Lekawa ME, Dolich MO, Cinat ME, Barrios C, Hoyt DB. Standard prophylactic enoxaparin dosing leads to inadequate anti-Xa levels and increased deep venous thrombosis rates in critically ill trauma and surgical patients. J Trauma 2010;68(4):874-80. doi:10.1097/ TA.0b013e3181d32271

12. Guyatt GH, Akl EA, Crowther M, Gutterman DD, Schuünemann HJ. Executive summary: Antithrombotic Therapy and Prevention of Thrombosis, 9th ed: American College of Chest Physicians EvidenceBased Clinical Practice Guidelines. Chest 2012;141(2 Suppl):7S-47S. doi:10.1378/chest.1412S3

13. Costantini TW, Min E, Box K, Tran V, Winfield RD, Fortlage D, Doucet J, Bansal V, Coimbra R. Dose adjusting enoxaparin is necessary to achieve adequate venous thromboembolism prophylaxis in trauma patients. J Trauma Acute Care Surg 2013;74(1):128-33; discussion 134-5. doi:10.1097/TA.0b013e3182788fa7

14. Singer GA, Riggi G, Karcutskie CA, Vaghaiwalla TM, Lieberman HM, Ginzburg E, Namias N, Lineen EB. Anti-Xa-guided enoxaparin thromboprophylaxis reduces rate of deep venous thromboembolism in high-risk trauma patients. J Trauma Acute Care Surg 2016;81(6):1101-08. doi:10.1097/TA.0000000000001193

15. Kakkar AK, Cimminiello C, Goldhaber SZ, Parakh R, Wang C, Bergmann J-F. Low-Molecular-Weight Heparin and Mortality in Acutely III Medical Patients. N Engl J Med 2011;365(26):2463-72. doi:10.1056/NEJMoa1111288

16. Wei MY, Ward SM. The anti-factor Xa range for low molecular weight heparin thromboprophylaxis. Hematol Rep 2015;7(4):8083. doi: $10.4081 / \mathrm{hr} .2015 .5844$

17. Schulman S, Kearon C. Definition of major bleeding in clinical investigations of antihemostatic medicinal products in non-surgical patients. J Thromb Haemost 2005;3(4):692-94. doi:10.1111/j.15387836.2005.01204.x

18. Schulman S, Anger SU, Bergqvist D, Eriksson B, Lassen MR, Fisher W. Definition of major bleeding in clinical investigations of antihemostatic medicinal products in surgical patients. J Thromb Haemost 2010;8(1):202-4. doi:10.1111/j.1538-7836.2009.03678.x

19. Ko A, Harada MY, Barmparas G, Chung K, Mason R, Yim DA, Dhillon N, Margulies DR, Gewertz BL, Ley EJ. Association Between Enoxaparin Dosage Adjusted by Anti-Factor Xa Trough Level and Clinically Evident Venous Thromboembolism After Trauma. JAMA Surg 2016;151(11):1006. doi:10.1001/jamasurg.2016.1662 